\title{
Cooperação global sobre mudanças climáticas e a implementação do ODS 6 no Brasil
}

\author{
Global cooperation on climate change and implementation of SDG 6 in Brazil \\ Cooperación global sobre cambio climático e implementación del ODS 6 en Brasil
}

Recebido: 24/02/2021 | Revisado: 03/03/2021 | Aceito: 08/03/2021 | Publicado: 16/03/2021

\author{
Norma Barbado \\ ORCID: https://orcid.org/0000-0002-0562-3958 \\ Instituto Federal de Educação, Ciência e Tecnologia do Paraná, Brasil \\ E-mail: norma.barbado@ifpr.edu.br \\ Antonio Cezar Leal \\ ORCID: https://orcid.org/0000-0002-7962-518X \\ Universidade Estadual Paulista Júlio de Mesquita Filho, Brasil \\ E-mail: cezar.leal@unesp.br
}

\begin{abstract}
Resumo
As mudanças climáticas se tornaram importante pauta nos cenários nacionais e internacionais a partir da década de 1970. Assim, vários eventos foram organizados para discutir questões ambientais, em todos os seus contextos, com uma sucessão de negociações multilaterais que priorizavam o compromisso com a sustentabilidade. Em 2015 foram aprovados os 17 Objetivos do Desenvolvimento Sustentável (ODS), com 169 metas, como parte da Agenda 2030. Destaca-se, nesse estudo, o ODS 6, com oito metas relacionadas à importância de assegurar a disponibilidade e gestão sustentável da água e saneamento para todos. Nessa perspectiva, o objetivo do trabalho foi caracterizar os principais eventos internacionais sobre mudanças climáticas e a responsabilidade global e discutir a implantação das metas do ODS 6 no Brasil. Para tanto, utilizou-se o método sistemático, com investigações bibliográficas, normativas e documentais. Constatou-se que as questões hídricas estão permanentemente incluídas nas agendas governamentais, visto que a água é um recurso essencial para a manutenção da vida, da saúde e das atividades humanas. No Brasil, pode-se inferir que apesar da parcial implantação das metas do ODS 6, ainda há muitas lacunas e desafios para sua total efetivação.
\end{abstract}

Palavras-chave: ODS 6; Agenda 2030; Agência Nacional das Águas e Saneamento Básico.

\begin{abstract}
Climate change has become an important issue in national and international scenarios since the 1970s. Thus, several events were organized to discuss environmental issues, in all their contexts, with a succession of multilateral negotiations that prioritized the commitment to sustainability. In 2015, the 17 Sustainable Development Goals (SDGs) were approved, with 169 targets, as part of the 2030 Agenda. In this study, SDG 6 stands out, with eight objectives related to the importance of ensuring the availability and sustainable management of water and sanitation for all. In this perspective, the objective of the work was to characterize the main international events on climate change and global responsibility and to discuss the implementation of the goals of SDG 6 in Brazil. For that, the systematic method was used, with bibliographic, normative and documentary investigations. It was found that the issue of water is permanently included in government agendas, since water is an essential resource for the maintenance of life, health and human activities. In Brazil, it can be inferred that despite the partial implementation of the goals of SDG 6, there are still many gaps and challenges for their full implementation.
\end{abstract}

Keywords: SDG 6; 2030 Agenda; National Water and Sanitation Agency.

\section{Resumen}

El cambio climático se ha convertido en un tema importante en los escenarios nacionales e internacionales desde la década de 1970. Así, se organizaron varios eventos para discutir temas ambientales, en todos sus contextos, con una sucesión de negociaciones multilaterales que priorizaron el compromiso con la sostenibilidad. En 2015 se aprobaron los 17 Objetivos de Desarrollo Sostenible (ODS), con 169 metas, como parte de la Agenda 2030. En este estudio se destaca el ODS 6, con ocho objetivos relacionados con la importancia de asegurar la disponibilidad y gestión sostenible del agua y saneamiento para todos. En esta perspectiva, el objetivo del trabajo fue caracterizar los principales eventos internacionales sobre cambio climático y responsabilidad global y discutir la implementación de las metas del ODS 6 en Brasil. Para ello se utilizó el método sistemático, con investigaciones bibliográficas, normativas y documentales. Se encontró que los temas del agua están incluidos de manera permanente en las agendas gubernamentales, ya que el agua es un recurso fundamental para el mantenimiento de la vida, la salud y las actividades humanas. En Brasil, se puede inferir que a pesar de la implementación parcial de las metas del ODS 6, aún existen muchas brechas y desafíos para su plena implementación.

Palabras clave: ODS 6; Agenda 2030; Agencia Nacional del Agua y Saneamiento Básico. 


\section{Introdução}

O Painel Intergovernamental de Mudanças Climáticas (Intergovernamental Panel Climate Change - IPCC) foi criado em 1988. No entanto, seus relatórios só foram disponibilizados à população após a divulgação pela mídia de alguns de seus dados e perspectivas futuras quanto ao aumento dos Gases do Efeito Estufa $\left(\mathrm{GEE}^{1}\right)$ e o aquecimento global, necessitando de decisões urgentes pelos governos e sociedade (Jacobi, Guerra, Sulaiman, \& Napomuceno, 2011).

No intuito de estabilizar os efeitos das mudanças climáticas, no âmbito do Sistema das Nações Unidas, a ConvençãoQuadro das Nações Unidas sobre a Mudança do Clima, do original United Nations Framework Convention on Climate Change (UNFCCC), busca entrelaçar o regime climático com a governança global ambiental. Essa interação corrobora para a mediação de conflitos e maior cooperação entre os Estados nacionais, no mundo globalizado, interdependente e complexo (Rei, Gonçalves, \& Souza, 2007). Nessa direção, Camargo (2015) afirma que para concretização do objetivo de estabilização climática, é fundamental considerar a governança como instrumento de participação ampliada, envolvendo atores estatais e não estatais, para elaboração, em consenso e persuasão, da sua autorregulamentação ancorada num arranjo institucional permanente.

Essa preocupação levanta muitos questionamentos a respeito da eficácia do regime de mudanças climáticas. O regime internacional constituído pelos Estados, considerados conservadores até a Conferência das Nações Unidas sobre as Mudanças Climáticas de 2015 (COP-21), possui um grande desafio de conduzir e induzir ações necessárias (principalmente de reduções de emissões de GEE) a tempo de evitar uma ruptura do sistema climático global. Além disso, é preciso considerar que essas ações podem não ser suficientes para evitar a possível ocorrência de eventos catastróficos ou sistêmicos, originados de um novo estado de equilíbrio da atmosfera ou de seu realinhamento (Rei et al., 2017).

De acordo com Nobre et al. (2007), os biomas podem ser alterados a partir da combinação sinergética dos impactos climáticos regionais decorrentes dos desmatamentos e do, consequente, aquecimento global. Segundo o autor, isso implica em temperaturas mais altas, ambientes mais secos e maior propensão a incêndios florestais. Jacobi et al. (2011) também afirmam que este cenário amplifica a vulnerabilidade dos ecossistemas, especificamente na distribuição dos biomas, influenciando na biodiversidade, na agricultura e nos recursos hídricos.

Diante do exposto, surgem necessidades de intensa cooperação, com foco principal nas mudanças climáticas, principalmente em bacias hidrográficas compartilhadas por vários países. Os acordos internacionais na gestão das bacias hidrográficas são frutos de discussões com diagnósticos e análises de problemas, objetivando a elaboração de propostas de soluções conjuntas (Tundisi, 2003; Somlyódy \& Varis, 2006). Assim, as convenções tornaram-se extremamente relevantes, resultando em tratados entre países com seus desdobramentos nos contextos subnacionais, mediante a prioridade da agenda política global (Bernauer, 2013). Segundo Alcântara et al. (2020), as grandes discussões sobre as recentes mudanças climáticas mostram que seus impactos não se refletem apenas nos grandes desastres ocasionados por eventos extremos, mas também no contexto econômico e social.

Os Objetivos do Desenvolvimento Sustentável (ODS) são parte da Resolução 70/1, da Assembleia Geral das Nações Unidas: "Transformando o nosso mundo: a Agenda 2030 para o Desenvolvimento Sustentável”, conhecida por Agenda 2030. Os ODS resultam de uma sucessão de negociações multilaterais, marcadas pela priorização do compromisso com a sustentabilidade na cooperação internacional para o desenvolvimento pelas Nações Unidas (Bezerra, 2019). Em 2015, foram aprovados os 17 ODS, abrangendo questões de desenvolvimento econômico e social, incluindo temas como justiça social, pobreza, saúde, fome, educação, aquecimento global, igualdade de gênero, água, saneamento, energia, urbanização e meio ambiente. Como parte desses objetivos, foram estabelecidas 169 metas amplas e interdependentes que contribuem para a

${ }^{1} \mathrm{~A}$ queima de combustíveis fósseis é responsável por mais de $75 \%$ das emissões de $\mathrm{CO}_{2}$ na atmosfera. A ocupação e o uso do solo, desmatamento e degradação de florestas são responsáveis pelo restante (Jacobi et al., 2011). 
Agenda de Desenvolvimento Pós-2015 (ONU, 2015).

No Brasil, o trabalho de adequação das metas estipuladas nos ODS parte da análise crítica e do cruzamento com as estratégias, planos e programas nacionais, além dos desafios do País para garantir o desenvolvimento sustentável. Quando se trata de recursos hídricos e saneamento, em uma perspectiva integrada, destacam-se as oito metas do ODS 6, que visam "assegurar a disponibilidade e gestão sustentável da água e saneamento para todas e todos". Para contribuir com o processo de monitoramento dessas metas, a Agência Nacional das Águas e Saneamento Básico (ANA), em parceria com diversas instituições, produz e sistematiza as informações utilizadas para cálculo de importantes indicadores (ANA, 2019 a). Assim, a ANA efetua o acompanhamento sistemático e periódico da condição dos recursos hídricos e de sua gestão no País por meio de estatísticas e indicadores que alimentam o Sistema Nacional de Informações sobre Recursos Hídricos (SNIRH).

Nessa perspectiva, esse estudo teve como objetivo caracterizar os principais eventos internacionais sobre mudanças climáticas e a responsabilidade global e discutir a implantação das metas do ODS 6 no Brasil.

\section{Metodologia}

O método utilizado foi o sistemático, por meio de investigações bibliográficas, documentais e normativas. De acordo com Gil (2002), uma das principais vantagens da revisão bibliográfica está no fato de permitir aos investigadores a cobertura de uma gama de fenômenos muito mais ampla do que aquela que poderia pesquisar diretamente. Trata-se de uma pesquisa qualitativa, já que considera importante a interpretação por parte dos pesquisadores, permitindo suas opiniões sobre o fenômeno em estudo (Pereira, Shitsuka, Parreira, \& Shitsuka, 2018). A análise dos dados descritivos ocorreu de forma indutiva, conforme recomendam Pereira et al. (2018). Essa metodologia foi definida partindo da observação da escassez de publicações que contemplassem, de forma sistematizada, os conteúdos a respeito das mudanças climáticas e responsabilidade global e, ainda, sobre a implementação das metas do ODS 6 no Brasil.

O texto foi organizado com a seguinte sequência: 1) Introdução; 2) Metodologia; 3) Resultados e Discussão; 3.1) Mudanças climáticas e a responsabilidade global; 3.2) Os Objetivos do Desenvolvimento Sustentável (ODS); 3.2.1) Implementação das metas do ODS 6 no Brasil; 4) Considerações Finais.

\section{Resultados e Discussão}

\subsection{Mudanças climáticas e a responsabilidade global}

A crise ambiental vivenciada nas últimas décadas tem origem em diversos fatores naturais e antrópicos. Ela deve ser caracterizada não apenas no viés ambiental, mas também social, já que é fruto de uma série de relações sociopolíticas (Silva \& Samora, 2019). Segundo o IPCC (2014), o aumento da temperatura média da atmosfera ocasiona grande preocupação devido aos extensos impactos ambientais provocados pelo aquecimento global, como o derretimento dos polos, o aumento do nível do mar e a ocorrência de desastres naturais. Além disso, os extremos climáticos (ondas de calor, invernos rigorosos, enchentes, furacões, secas, entre outros) também propiciam consequências diretas ao bem-estar da população e aos ecossistemas naturais (Marengo et al., 2015).

A adaptação às mudanças climáticas globais e a mitigação dos seus efeitos são grandes desafios. $\mathrm{O}$ avanço da ciência e da tecnologia, que contribuiu para melhor qualidade de vida da população (geração de eletricidade, transporte de passageiros e mercadorias, produção de alimentos, entre outros benefícios) trouxe também efeitos nocivos, envolvendo a emissão de GEE. Como afirmam Assad, Martins, Cordeiro e Evangelista (2019, p. 156):

As definições e conceitos indicam que o clima na Terra é regulado pelo fluxo constante de energia solar que atravessa a atmosfera na forma de luz visível e de raios ultravioletas. Parte dessa energia é devolvida pela Terra na forma de 
radiação infravermelha. Os GEE são gases presentes na atmosfera terrestre que têm a propriedade de bloquear parte dessa radiação infravermelha. Muitos deles, como vapor d'água, $\mathrm{CO}_{2}, \mathrm{CH}_{4}$ e $\mathrm{N}_{2} \mathrm{O}$ e ozônio $\left(\mathrm{O}_{3}\right)$, existem naturalmente na atmosfera e são essenciais para a manutenção da vida no planeta. Sem eles a Terra seria, em média, cerca de $30{ }^{\circ} \mathrm{C}$ mais fria.

Em virtude da proporção global das alterações climáticas, a comunidade internacional, por intermédio da UNFCCC, busca o enfrentamento do aquecimento global, colocando em pauta a garantia da preservação ambiental para as presentes e futuras gerações (Neves \& Bizawu, 2019).

Para compreender as consequências ambientais das escolhas da sociedade, devem ser considerados vários fatores como as tomadas de decisão, a articulação das ações coletivas, o engajamento individual às mobilizações coletivas e as relações internacionais, ressignificando a compreensão acerca das complexas relações entre a capacidade de ação e construções sociais (Keohane \& Victor, 2011; Beeson \& Mc Donald, 2013; Fleury, Miguel, \& Taddei, 2019). Nesse contexto, Fleury et al. (2019) esclarecem que as análises dos processos de negociação das Conferências Mundiais do Clima, ou Conferências das Partes da Convenção, UNFCCC, conhecidas por sua sigla COP, estão conquistando maior espaço entre os cientistas sociais, especialmente no âmbito dos Estudos Sociais em Ciência e Tecnologia. Os autores relatam que esses fóruns mundiais (COP) ocorrem anualmente, com representantes dos países que ratificaram esta convenção, bem como cientistas e representantes de distintos setores da sociedade civil, que se reúnem para debater e propor acordos globais.

Assim, todas as discussões ocorridas nos eventos internacionais (Quadro 1), aliados às pesquisas científicas sobre mudanças climáticas em todos os seus contextos, corroboram com a preocupação de Carvalho (2011) sobre os recursos naturais serem finitos e de, praticamente, impossível recuperação. O autor destaca que a humanidade não pode alegar desconhecimento sobre práticas que interferem na perpetuação da vida na Terra.

Quadro 1: Eventos internacionais sobre questões climáticas e a responsabilidade global.

\begin{tabular}{|c|c|}
\hline Ano & Eventos sobre o clima e suas características (nome, local de realização, assuntos abordados) \\
\hline 1972 & $\begin{array}{l}\text { onferência das Nações Unidas sobre o Meio Ambiente [ou Ambiente Humano], em Estocolmo (Suécia), organizado pelo Programa das Nações } \\
\text { Inidas para o Meio Ambiente (PNUMA), criado no mesmo ano (1972), com sede no Quênia (África Oriental). A conferência resultou na Declaração } \\
\text { e Estocolmo sobre o ambiente humano - 1972, com } 26 \text { princípios comuns na busca de um equilíbrio global que pudessem servir de exemplo para } \\
\text { uiar os povos do mundo na preservação e melhoria do meio ambiente. }\end{array}$ \\
\hline 1988 & $\begin{array}{l}\text { Primeira Conferência Mundial sobre o Clima, em Toronto (Canadá), organizado pelo Painel Intergovernamental sobre Mudanças Climáticas (IPCC), } \\
\text { com uma alerta dos cientistas para a necessidade de reduzir os gases do efeito estufa. }\end{array}$ \\
\hline 1990 & $\begin{array}{l}1^{\circ} \text { Relatório do IPCC com a divulgação sobre o aumento da temperatura do planeta, em Genebra (Suíça). A projeção era de cerca de } 0,15^{\circ} \mathrm{C} \text { e } 0,3^{\circ} \mathrm{C} \\
\text { para a década seguinte. Ficou estabelecida a necessidade de um tratado internacional climático (produzido em 1992). Além disso, foi criado o Comitê } \\
\text { Intergovernamental de Negociação para uma UNFCCC. }\end{array}$ \\
\hline 1992 & $\begin{array}{l}\text { Conferência das Nações Unidas para o Meio Ambiente e o Desenvolvimento (CNUMAD, Rio-92 ou Eco-92), no Rio de Janeiro (Brasil). O evento } \\
\text { resultou nos seguintes tratados internacionais: Agenda 21; Convenção da Biodiversidade; UNFCCC, com o objetivo de estabilizar a concentração de } \\
\text { gases do efeito estufa na atmosfera. Além disso, no evento paralelo da Cúpula da Terra (Rio-92), chamado de "Fórum Global", foi redigida a } \\
\text { primeira versão da Carta da Terra, ao lado de um conjunto de documentos chamados de "Tratados" das ONGs. }\end{array}$ \\
\hline 1995 & $\begin{array}{l}1^{\text {a }} \text { Conferência das Partes (COP-1), em Berlim (Alemanha), resultando em compromissos legais de redução de emissões, que fariam parte do } \\
\text { Protocolo de Kyoto e no } 2^{\circ} \text { relatório do IPCC. Para que tivesse efeito, o Protocolo de Kyoto teria que ser ratificado pelos países desenvolvidos, cuja } \\
\text { soma de emissões de } \mathrm{CO}_{2} \text { representava 55\% do total. Nesse sentido, houve divergência entre os Estados Unidos (EUA) e a União Europeia. }\end{array}$ \\
\hline 1996 & \\
\hline 1997 & $\begin{array}{l}3^{\text {a }} \text { Conferência das Partes (COP-3), em Kyoto (Japão). O Mecanismo de Desenvolvimento Limpo (MDL) foi criado, a partir de uma proposta } \\
\text { brasileira, além dos certificados de carbono. O Protocolo de Kyoto é um instrumento legal que sugere a redução de emissões de gases do efeito estufa } \\
\text { nos países signatários e, no caso dos grandes poluidores do mundo desenvolvido, impõe-se metas variadas de redução, sendo } 5,2 \% \text { em média, } \\
\text { tomando como parâmetro as emissões de } 1990 \text {. }\end{array}$ \\
\hline 1998 & das Partes (COP-4), em Buenos Aires (Argentina), com a discussão sobre cronograma para implementar o Protocolo de Kyoto. \\
\hline 1999 & tocolo de Kyoto. \\
\hline \multirow[t]{2}{*}{2000} & $\begin{array}{l}\text { Cúpula do Milênio, no mês de setembro, } \\
\text { século, refletindo as preocupações de } 147\end{array}$ \\
\hline & $\begin{array}{l}\text { gociações devido à tensão entre a União Europeia e o grupo liderado pelos EUA. No ano } \\
\text { iriam ratificar o Protocolo de Kyoto. }\end{array}$ \\
\hline 2001 & $\begin{array}{l}7^{\text {a }} \text { Conferência das Partes (COP-7), COP extraordinária convocada pelo IPCC, em Bonn (Alemanha) e Marrakesh (Marrocos). O evento resultou no } \\
3^{\circ} \text { Relatório do IPCC que evidencia a interferência do homem nas mudanças climáticas. A tensão entre os países industrializados diminui na COP-7, } \\
\text { em Marrakesh. }\end{array}$ \\
\hline \multirow[t]{2}{*}{2002} & \\
\hline & \\
\hline
\end{tabular}




\section{Ano $\quad$ Eventos sobre o clima e suas características (nome, local de realização, assuntos abordados)}

progresso dos acordos estabelecidos na Rio-92, a partir da Agenda 21. Demais temas discutidos: erradicação da pobreza, uso da água, manejo dos recursos naturais e desenvolvimento sustentável.

2003 9 $9^{\mathrm{a}}$ Conferência das Partes (COP-9), em Milão (Itália), em que se aprofundam as diferenç̧as entre os países industrializados e os demais países do mundo. Fica clara a falta de lideranças comprometidas para costurar acordos, o que é cobrado por ONGs. O assunto "florestas" entra em pauta.

$200410^{\mathrm{a}}$ Conferência das Partes (COP-10), em Buenos Aires (Argentina), com discussões sobre novos compromissos de longo prazo a partir de 2012, quando vence o primeiro período do Protocolo de Kyoto.

$2005 \quad 11^{a}$ Conferência das Partes (COP-11), em Montreal (Canadá), com a necessidade de um amplo acordo internacional, visto que Brasil, China e Índia se tornaram emissores importantes. Foi proposta pelo Brasil a negociação em dois trilhos: o pós-Kyoto e outra paralela entre os grandes emissores, o que incluía os EUA.

2006 12 $2^{\text {a }}$ Conferência das Partes (COP-12), em Nairóbi (Quênia), com a vulnerabilidade dos países mais pobres ficando evidente. O Brasil apresenta a proposta de um mecanismo de incentivos financeiros para a manutenção das florestas, o Redução de Emissões por Desmatamento e Degradação (REDD). Ainda repercute o Relatório Stern (Inglaterra, 2006) com o estudo econômico sobre os prejuízos do aquecimento global.

2007 13 $3^{\text {a }}$ Conferência das Partes (COP-13), em Bali (Indonésia), com a proposta de criação de um fundo de recursos para os países em desenvolvimento e as Ações de Mitigação Nacionalmente Adequadas (NAMAS). Esse modelo de ações foi considerado ideal, mesmo sem obrigação legal, contribuiu para que os países concordassem em diminuir suas emissões. Foi elaborado o Mapa do Caminho, apresentando cinco pilares de discussão para facilitar a assinatura de um compromisso internacional em Copenhague: visão compartilhada, mitigação, adaptação, transferência de tecnologia e suporte financeiro.

$200814^{\text {a }}$ Conferência das Partes (COP-14), em Poznan (Polônia), continuando os ajustes para um acordo amplo em Copenhague, sem muitos avanços. O Brasil lança o Plano Nacional sobre Mudança do Clima (PNMC), incluindo metas para a redução do desmatamento. Apresenta, ainda, o Fundo Amazônia, iniciativa para captar recursos para projetos de combate ao desmatamento e de promoção da conservação e uso sustentável na região.

2009 15 a Conferência das Partes (COP-15), em Copenhague (Dinamarca). Esse encontro teve como objetivo a elaboração de um novo tratado que substituiria o Protocolo de Kyoto. A primeira etapa do novo tratado só se encerrou em 2012 . Meta: fixar a elevação da temperatura da Terra em $2{ }^{\circ} \mathrm{C}$ até 2020, evitando consequências extremas. Ressalta-se que apenas um grupo restrito, formado por chefes de estado, traçou uma proposta de acordo.

$201016^{\mathrm{a}}$ Conferência das Partes (COP-16), em Cancún (México). Na ocasião, Japão, Canadá e Rússia anunciaram que não participariam de um segundo período de compromisso com metas ambiciosas no âmbito do Protocolo de Kyoto. Acordos de Cancún: manutenção da meta da COP-15; formação de um Comitê Executivo de Tecnologia operacional até 2012; criação de um Fundo Verde para o Clima; estabelecimento do Quadro de Adaptação de Cancún. O único país a se opor aos documentos foi a Bolívia.

2011 17 Conferência das Partes (COP-17), em Durban (África do Sul), com decisão de adotar um acordo legal universal sobre mudanças climáticas o mais rápido possível, e o mais tardar em 2015. Também houve discussão sobre: Protocolo de Kyoto, Plano de Ação de Bali e Acordos de Cancún.

$201218^{\text {a }}$ Conferência das Partes (COP-18), em Doha (Catar), com a decisão de estender o Protocolo de Kyoto para 2020.

Rio + 20: Conferência das Nações Unidas sobre Desenvolvimento Sustentável, Rio de Janeiro, Brasil, que contribuiu para definir a agenda do desenvolvimento sustentável para as próximas décadas. Documento resultante: "O futuro que queremos", abordando os temas: 1) A economia verde no contexto do desenvolvimento sustentável e da erradicação da pobreza; 2) A estrutura institucional para o desenvolvimento sustentável.

2013 19 Conferência das Partes (COP-19), em Varsóvia (Polônia), com decisões sobre o avanço da Plataforma de Durban, o Fundo Verde do Clima e Financiamento de Longo Prazo, a Estrutura de Varsóvia para REDD Plus, o Mecanismo Internacional de Varsóvia para Perdas e Danos, entre outras.

$201420^{a}$ Conferência das Partes (COP-20), em Lima (Peru). Países desenvolvidos e em desenvolvimento, antes e durante a COP-20, firmaram compromisso de capitalizar o novo Fundo Verde para o Clima (GCF) além da meta inicial de 10 bilhões de dólares. Os níveis de transparência e construção de confiança alcançaram novos patamares à medida que vários países industrializados se submeteram a questionamentos sobre suas metas de emissões em um novo processo denominado Avaliação Multilateral. O documento final da COP-20, denominado "Chamado de Lima para a Ação Climática" ou "Rascunho Zero", apela aos governos para que incluam a mudança climática nos currículos escolares e a conscientização climática nos planos de desenvolvimento nacional.

$2015 \quad 3^{a}$ Conferência Internacional sobre Financiamento ao Desenvolvimento, em Adis Abeba (Etiópia), resultando na Agenda de Ação de Adis Abeba, entendida como essencial para o planejamento do futuro dos ODS.

$21^{\text {a }}$ Conferência das Partes (COP-21), em Paris (França). A meta do Acordo de Paris foi manter o aumento da temperatura do planeta abaixo dos $2{ }^{\circ} \mathrm{C}$. Para que esse acordo entrasse em vigor, seria necessário que os países que representam em torno de 55\% da emissão de gases de efeito estufa ratificassem-no.

2016 22 $2^{\text {a }}$ Conferência das Partes (COP-22), em Bab Ighli, Marrakech (Marrocos). O evento resultou nos seguintes documentos: Proclamação de ação Marrakech para o clima e desenvolvimento sustentável; Parceria de Marrakech para Ação Global pelo Clima; Rastreador de progresso: Programa de trabalho resultante das solicitações relevantes contidas na decisão 1/COP-21.

$201723^{\text {a }}$ Conferência das Partes (COP-23), em Bonn (Alemanha). Foram discutidos os objetivos e ambições do Acordo de Paris, visando alcançar progresso em suas diretrizes de implementação. Também foi pauta a vulnerabilidade das ilhas e de todas as nações, comunidades resilientes e transição para o crescimento movido a energia limpa. Destaca-se que, na ocasião, os Estados Unidos deixaram de participar do Acordo de Paris.

2018 24 ${ }^{\text {a }}$ Conferência das Partes (COP-24), em Katowice (Polônia). O Pacote climático Katowice incluía: preparativos para a implementação do Acordo de Paris e a primeira sessão da COP servindo como a reunião das Partes do Acordo de Paris; Plataforma de Comunidades Locais e Povos Indígenas; Financiamento climático de longo prazo; Relatório da Comissão Permanente de Finanças; Relatório do Fundo Verde para o Clima e orientação para o Fundo Verde para o Clima; Relatório do Fundo Global para o Meio Ambiente e orientação para a Instalação desse fundo; Modalidades, programa de trabalho e funções no âmbito do fórum sobre o impacto da implementação de medidas de resposta; Planos de adaptação nacional; Relatório do Comitê de Adaptação; Relatório do Comitê Executivo de Varsóvia sobre o Mecanismo Internacional de Perdas e Danos associados aos impactos da mudança climática.

2019 25 Conferência das Partes (COP-25), em Madri (Espanha), com a revisão e relatório de todos os planos anteriores, propostas de melhorias no desenvolvimento e transferência de tecnologia climática, orçamentos e cronogramas futuros. Entretanto, a COP-25 chegou ao último dia sem acordo e as pendências foram adiadas para a COP-26, prevista para o final de 2020.

2020 Todos os eventos aconteceram de forma virtual, devido à Pandemia de Covid-19. Os diálogos sobre o clima, tiveram como objetivo avançar o trabalho dos órgãos subsidiários e da COP, abrindo caminho para uma COP-26 (prevista para 2020 e adiada para 2021, em Glasgow, Escócia). Assim, ocorreu o Momento de Junho para eventos de mudança climática e os Diálogos sobre Mudança Climática da ONU 2020. Um desses diálogos, o Climate Ambition Summit, foi uma reunião realizada no mês de dezembro em que chefes de estado apresentaram metas ambiciosas para cumprirem o compromisso de zerar as emissões de carbono até a metade do século 21, previsto no Acordo de Paris. No entanto, entre os grandes poluidores mundiais que ficaram de fora estavam Brasil, México e EUA. 
(EUA), estava há anos deixando de firmar compromissos relacionados às mudanças climáticas. Nesse sentido, houve divergências a respeito do Protocolo de Kyoto na COP-1, em 1995, compromisso que não foi ratificado pelo presidente americano na COP-6, em 2000. Além disso, em 2017, os EUA deixaram de participar do Acordo de Paris sobre mudanças climáticas, apesar dos compromissos firmados em 2015. Na ocasião, o então presidente americano sugeriu abrir negociações para um "melhor acordo", porém os líderes europeus não concordaram. No entanto, no dia 19 de fevereiro de 2021, após quase um mês da posse, o novo presidente dos EUA anunciou a reintegração oficial do país no Acordo de Paris, marcando a retomada da Casa Branca aos esforços mundiais de combate às mudanças climáticas, com o compromisso de zerar emissões de gases estufa do país até 2050 (USA, 2021).

O Brasil, na COP-25, em Madrid (ES) no ano de 2019, atuou sem protagonismo e liderança. Em bloco, junto com a África do Sul, China e Índia (quarteto conhecido como Basic), ocorreram as negociações de maneira combinada nas conferências do clima desde 2009. Na COP-25, o Basic fez oposição ao grupo liderado, entre outros países, pela Costa Rica. No entanto, em 2019, ocorreu uma série de incêndios florestais que afetaram a América do Sul, principalmente o Brasil, enquanto a Costa Rica recebia o prêmio Campeões da Terra de 2019, o maior reconhecimento ambiental da ONU, por seu papel na proteção da natureza e seu compromisso com políticas ambiciosas para o combate às mudanças climáticas.

A partir de 2020, o Brasil, quinto maior poluidor do mundo (Barbi, 2017), anulou o compromisso de zerar as emissões de carbono até a metade do século 21, previsto no Acordo de Paris. A meta do Brasil, atualizada pelo Ministério do Meio Ambiente, foi definida em dezembro de 2015, quando o Acordo de Paris reuniu países que aceitaram se comprometer com o esforço de limitar o aquecimento global a $1,5^{\circ} \mathrm{C}$. Na reunião preparatória para a COP-26, ocorrida em dezembro de 2020 , vários chefes de Estado discursaram sobre suas metas (Climate Ambition Summit, 2020).

De acordo com uma análise do Observatório do Clima, rede de 56 organizações da sociedade civil, a nova meta climática apresentada pelo Ministro do Meio Ambiente brasileiro ao Acordo de Paris, permitiria ao País chegar a 2030 emitindo 400 milhões de toneladas de gases do efeito estufa a mais do que o previsto na meta original. A meta de redução de 2015 era baseada no Segundo Inventário de Emissões de Gases de Efeito Estufa. Já a meta atual tem como base o Terceiro Inventário, que atualizou o valor absoluto dos gases emitidos em 2005 de 2,1 bilhões de toneladas para 2,8 bilhões de toneladas de gases emitidos. Ademais, o observatório classificou como "chantagem" a afirmação do Ministro do Meio Ambiente de que o prazo para alcançar a neutralidade de carbono nos próximos 40 anos poderia ser antecipado, caso os países desenvolvidos transferissem 10 bilhões de dólares anuais para projetos brasileiros a partir de 2021 (Observatório do Clima, 2020).

Entre as importantes questões constantes nos documentos resultantes das negociações relatadas no Quadro 1, verificase também que as questões hídricas são incluídas nas agendas governamentais de forma permanente, considerando-se que a água é um recurso essencial para a manutenção da vida, da saúde e das atividades humanas. Nesse sentido, a ONU desempenha uma função primordial, no intuito de assegurar, no mínimo, o abastecimento de água às populações em todos os locais habitados. Nessa direção, durante a Cúpula do Milênio, relatada no Quadro 1, foram analisados os maiores problemas mundiais, resultando em metas (Figura 1) para tornar o mundo melhor e mais justo até 2015. Assim, líderes de 191 nações, incluindo o Brasil, tornaram-se signatários desse pacto que visava cumprir oito iniciativas, conhecidas como Objetivos de Desenvolvimento do Milênio (ODM). 
Figura 1: Objetivos de Desenvolvimento do Milênio (ODM).

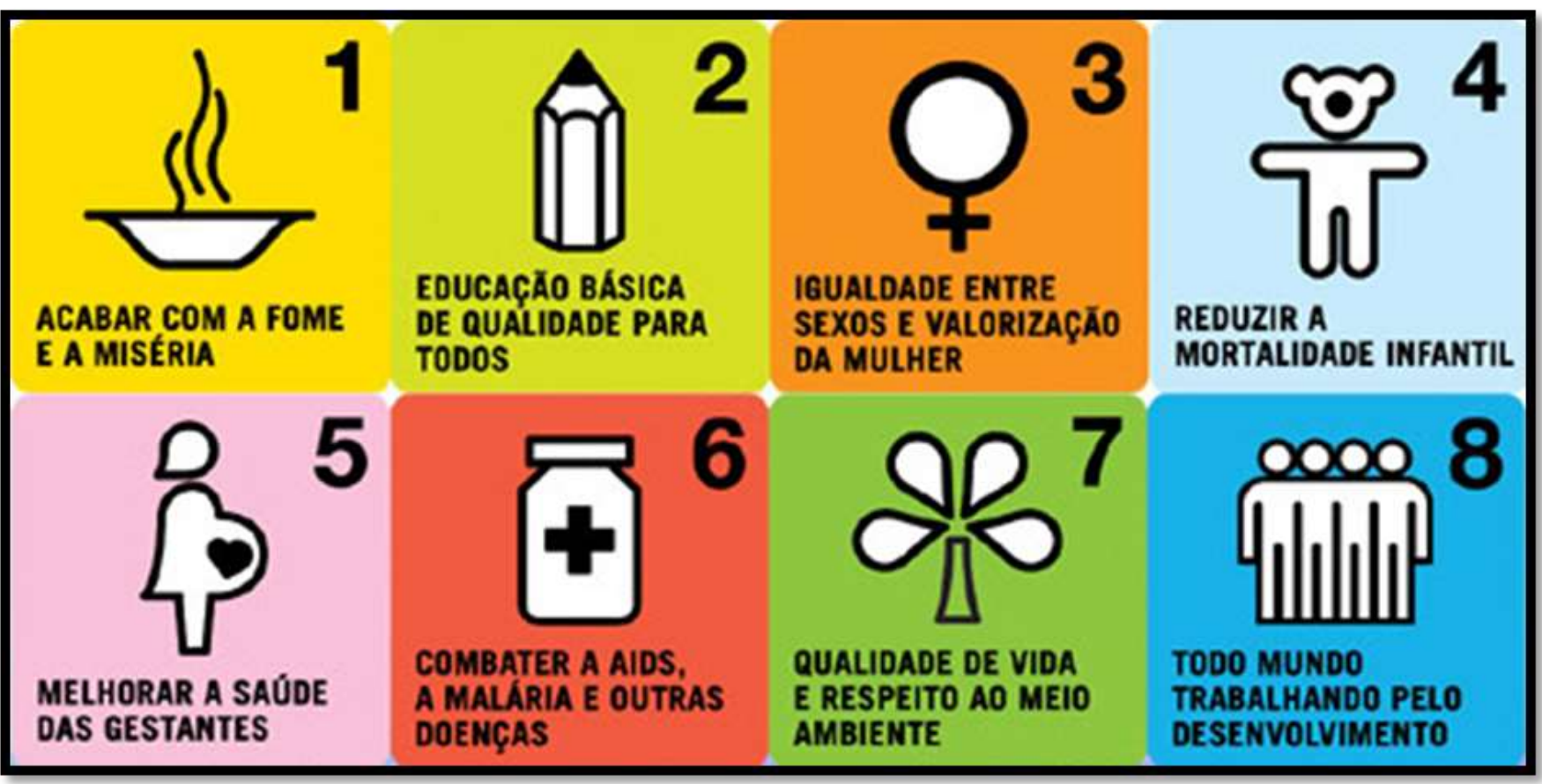

Fonte: ODM Brasil (2000).

Ressalta-se que os ODS e os oito ODM (Figura 1) fixaram metas semelhantes entre 2000 e 2015 (Granziera \& Silva, 2019). Na Conferência Rio + 20, em 2012, com o estabelecimento de condições básicas para uma construção coletiva de um novo conjunto de objetivos e metas, as experiências de êxito dos ODM foram ampliadas. Todavia, Bezerra (2019) descreve que o reconhecimento da aplicabilidade dos objetivos e metas a todos os países, mesmo os mais desenvolvidos, implicou em aceitar que nenhum país havia alcançado o desenvolvimento de forma sustentável e que todos teriam que prestar contas. Segundo o autor, o núcleo da Agenda 2030 foi constituído a fim de elaborar uma proposta de objetivos e metas de desenvolvimento sustentável, a partir de treze encontros formais ocorridos nos anos de 2013 e 2014. Esse trabalho resultou em um documento denominado Report of the Open Working Group of the General Assembly on Sustainable Development Goals, apresentado na $69^{\circ}$ Assembleia Geral da ONU, em 2014.

No ano seguinte (2015), em Nova Iorque (EUA), foi proposta a Agenda 2030, com um conjunto de programas, ações e diretrizes no intuito de orientar os trabalhos das Nações Unidas e de seus Estados-Membros rumo ao desenvolvimento sustentável, considerando os aspectos sociais, econômicos e ambientais (ANA, 2019 a). Dessa forma, os ODS objetivam orientar as atividades de cooperação internacionais e as políticas nacionais, sucedendo e atualizando os ODM (UNCT, 2015).

$\mathrm{O}$ ano de 2020 seria um ano-chave para o planeta, no entanto a pandemia da Covid-19 (causada pelo coronavírus) afetou especialmente a China e países europeus, onde estavam programados encontros internacionais com o objetivo de assinar novos compromissos ambientais. Em 2021, todas as reuniões da UNFCCC agendadas para março e abril já foram canceladas, tanto na sede em Bonn (Alemanha) como em outras partes do mundo, como a Semana Climática da África, que estava programada para 09 de março de 2021. Diante das incertezas em relação à pandemia, como destacado pela Fundação Ambiente Y Recursos Naturales (FARN, 2020), é preocupante a suspensão da agenda climática. Para uma COP-26 bem-sucedida, é necessário construir marcos que orientem a negociação para um bom resultado. Considerando o fracasso da COP-25, realizada no ano de 2019 em Madri (ES), sem nenhum entendimento formalizado, a COP-26 seria fundamental para avançar na implementação do Acordo de Paris, especialmente sobre a criação de um mercado internacional de carbono e a garantia de financiamento por parte de países desenvolvidos e em desenvolvimento (FARN, 2020). Segundo os principais estrategistas 
mundiais na economia política das mudanças climáticas (E3G, 2020), dedicados a alcançar um clima seguro para todos, muitas reuniões sobre mudanças climáticas ainda podem ser adiadas por causa da pandemia de Covid-19. Vale ressaltar que a maior parte das negociações ocorre nos corredores desses eventos, às margens das reuniões oficiais, portanto, substituir esses encontros por reuniões virtuais não seria o suficiente.

\subsection{Os Objetivos do Desenvolvimento Sustentável (ODS)}

O ano de 2015 foi marcado pelo fim do período delimitado para implementação dos ODM (Menezes, 2019), além de serem concluídas as negociações que levaram à aprovação dos ODS (Figura 2), com 17 objetivos e 169 metas, na 70a Assembleia Geral da ONU. Com a aprovação do documento denominado Transforming our world: the 2030 Agenda for Sustainable Development, associada à conclusão da Agenda de Ação de Adis Abeba e do Acordo de Paris, configurou-se uma nova agenda de desenvolvimento global, acentuando-se os aspectos sociais, econômicos e ambientais, com amplo compromisso global estabelecido.

Figura 2: Objetivos do Desenvolvimento Sustentável (ODS).

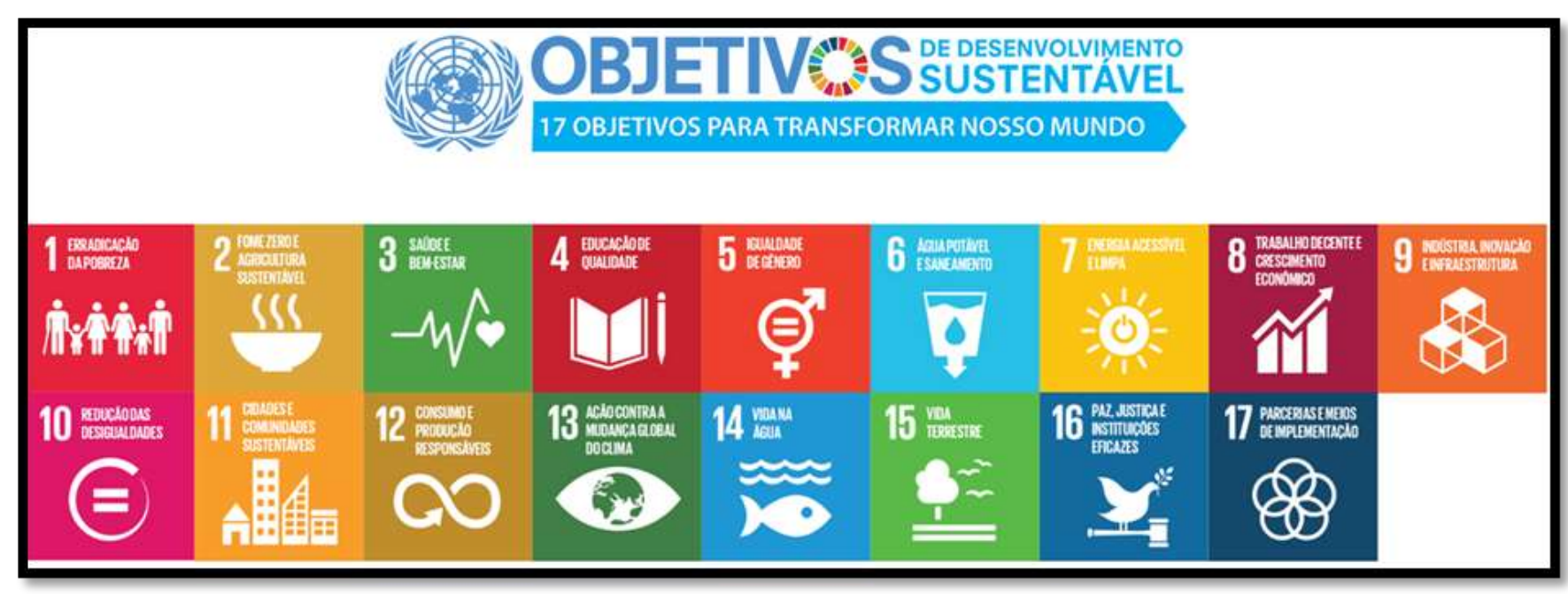

Fonte: Nações Unidas Brasil (UNCT, 2015)

Nesse contexto, os ODS (Figura 2) têm como base o sucesso alcançado pelos oito ODM (Figura 1), incluindo novos temas, como mudança global do clima (ODS 13), desigualdade socioeconômica (ODS 10), inovação tecnológica (ODS 9), consumo sustentável (ODS 12), paz e justiça (ODS 16). Assim, os ODS são mais abrangentes que os ODM, já que abordam mais elementos interligados ao desenvolvimento sustentável (ANA, 2019 a).

Ainda que a Agenda 2030 seja direcionada a todos os países signatários, cada país é responsável pelo alcance de suas metas específicas incluídas nos ODS. Para tanto, reforça-se a importância da parceria global, apoiando os objetivos e governos envolvidos na busca de recursos necessários para o cumprimento das metas estabelecidas (ONU, 2015). Essas medidas são relevantes, preventivas e repressivas, consideradas por Lima e Granziera (2018) como instrumentos de comando-controle. As autoras destacam que o estabelecimento de padrões ambientais para os recursos hídricos não impede nenhum risco ambiental e sua concretização, tornando-se necessária a valorização de atitudes voltadas à conservação da água e mecanismos capazes de mitigar a degradação ambiental e, consequentemente, melhorando as condições de atendimento às demandas do abastecimento público.

No debate sobre desenvolvimento sustentável, a denominada "agenda da água" se destacou por estar intimamente ligada a elementos sociais, econômicos e ambientais. As mudanças climáticas colocam em dúvida a resiliência e propriedade 
de adaptação dos ecossistemas e serviços estabelecidos (Galvão \& Monteiro, 2019). Segundo Lopes (2018), a água é o núcleo do desenvolvimento sustentável, conforme descrito no Quadro 2. Ressalta-se que, em 2017, cerca de 785 milhões de pessoas ao redor do mundo não tinham acesso mínimo à água potável e o número de pessoas desassistidas era ainda maior quando se trata dos serviços de coleta e tratamento de esgoto (UN-ECOSOC, 2019).

Quadro 2: A água e as três dimensões do desenvolvimento sustentável.

\begin{tabular}{|l|l|}
\hline $\begin{array}{l}\text { Sociedades pacíficas e } \\
\text { inclusivas }\end{array}$ & O acesso à água nas residências é crítico para a saúde das famílias e para a dignidade das pessoas. \\
\hline $\begin{array}{l}\text { Sustentabilidade } \\
\text { ambiental }\end{array}$ & $\begin{array}{l}\text { Foco mais holístico sobre ecossistemas para água e desenvolvimento que mantenha um equilíbrio } \\
\text { entre ambientes naturais e infraestrutura. }\end{array}$ \\
\hline $\begin{array}{l}\text { Sustentabilidade } \\
\text { econômica }\end{array}$ & $\begin{array}{l}\text { Abastecimento de água tem que ser confiável e previsível para apoiar financeiramente a } \\
\text { sustentabilidade de investimentos em atividades econômicas. }\end{array}$ \\
\hline
\end{tabular}

Fonte: Adaptado de Lopes (2018).

Os Indicadores Brasileiros para os Objetivos do Desenvolvimento Sustentável (ODS Brasil) são dados de acompanhamento e avaliação das ações de implementação da Agenda 2030. Esse monitoramento acontece, sistematicamente, nos níveis global, nacional e regional (ODS Brasil, 2021). Além desses indicadores, também são utilizados dados fornecidos pelo Instituto Brasileiro de Geografia e Estatística (IBGE), para verificar situações relacionadas aos ODS. Dessa forma, na revisão do Open Data Inventory (ODIN ${ }^{2}$ ) para o biênio 2020-2021, o Brasil obteve 62 pontos e subiu para a $47^{\text {a }}$ posição no ranking mundial. Em 2018, quando obteve 54 pontos, o país ocupava a $57^{\mathrm{a}}$ posição. Esse inventário fornece um panorama de oferta de 22 categorias de dados abertos em 187 países, agrupados em estatísticas sociais, econômico-financeiras e ambientais (ODIN, 2021).

\subsubsection{Implantação das metas do ODS 6 no Brasil}

De acordo com Tundisi e Matsumura-Tundisi (2015), os principais problemas e conexões da crise hídrica são ameaças resultantes de: enchentes e extremos de precipitação, seca ou deterioração da qualidade da água. Nesse contex to, o ODS 6, da Agenda 2030, se refere a "[...] assegurar a disponibilidade e gestão sustentável da água e saneamento para todos" (ONU, 2015). Como os assuntos relacionados à água apresentam um viés transversal, ODS 6 encontra-se integrado aos demais objetivos, como o ODS 2 (Fome Zero e Agricultura Sustentável), o ODS 3 (Saúde e Bem-Estar), ODS 7 (Energia Limpa e Acessível), o ODS 13 (Ação Contra a Mudança Global) e o ODS 14 (Vida na Água), entre outros (ANA, 2019 a).

Ainda que o texto do ODS 6 apresente aspectos ligados ao abastecimento humano e ao saneamento ambiental, este objetivo apresenta metas (Figura 3) que abrangem fatores relacionados aos recursos hídricos nas perspectivas: ambiental, sociocultural, econômica e de segurança (Galvão \& Monteiro, 2019). Os resultados dos indicadores do ODS 6 para o Brasil estão sendo trilhados de forma positiva na maioria de suas metas (ANA, 2019 a).

\footnotetext{
${ }^{2}$ O Open Data Inventory (ODIN) avalia a cobertura e abertura das estatísticas oficiais para identificar lacunas, promover políticas de dados abertos, melhorar o acesso e encorajar o diálogo entre os institutos nacionais de estatística (NSOs) e os usuários dos dados (ODIN, 2020).
} 
Figura 3: Metas do Objetivo do Desenvolvimento Sustentável número 6.

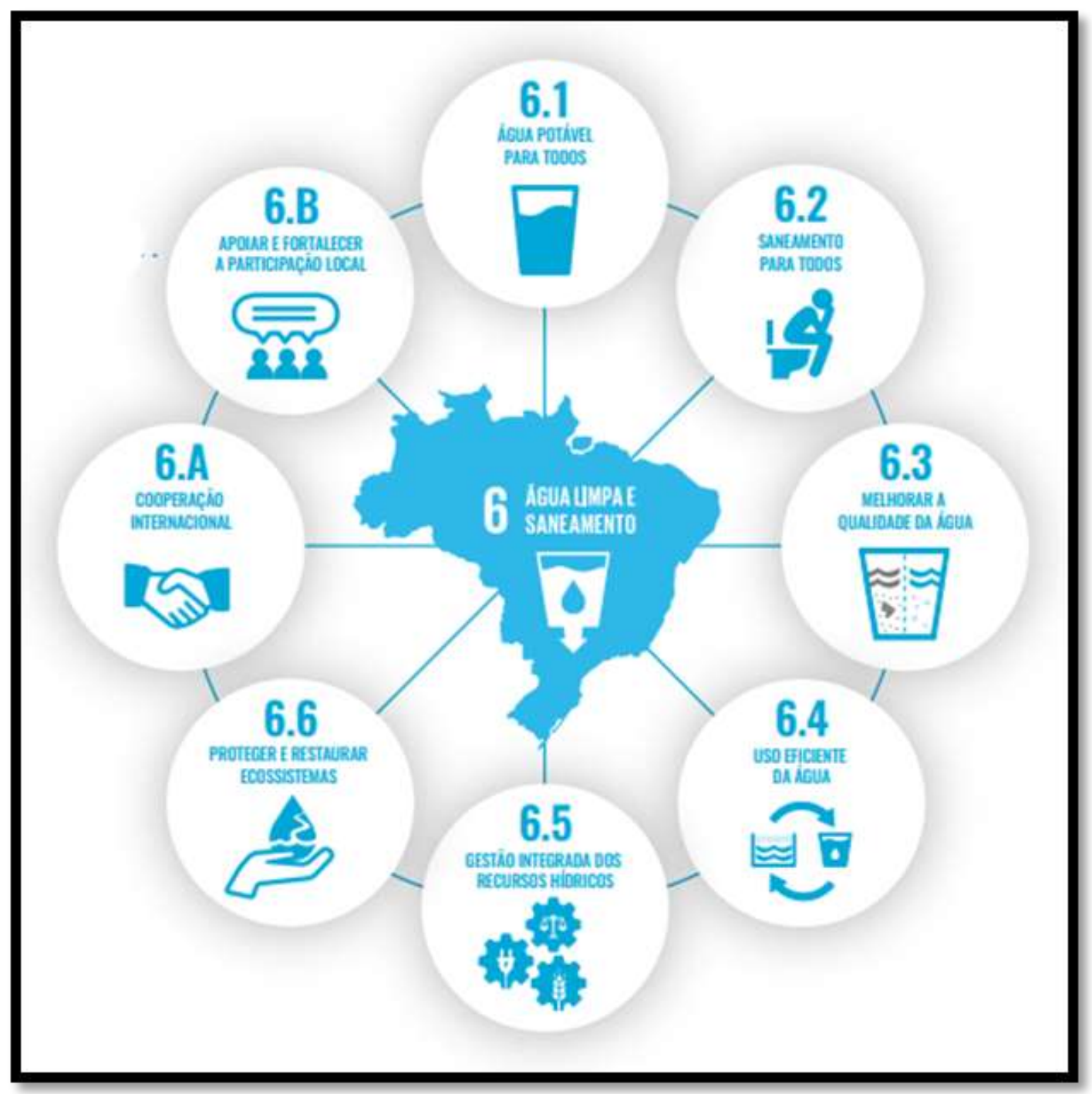

Fonte: ODS Brasil (2021).

Nesse cenário, a meta 6.1 (Figura 3) estabelece que, até 2030, ocorra o acesso universal e equitativo à água potável e segura para todos. No Brasil, até 2018, 95,1\% da população já utilizava os serviços de água potável geridos de forma segura (ANA, 2020). Todavia, o consumismo desenfreado da sociedade urbana e industrial pode transformar a abundância em escassez de água (BORDALO, 2012). De acordo com Richter (2015), os impactos econômicos dessa escassez podem influenciar o funcionamento dos sistemas de infraestrutura e na qualidade de vida, além de que o custo para obtenção de água adicional pode ser altíssimo.

Apesar desse problema crescente, a população ainda não está bem informada quanto à importância da economia de água, dificultando as políticas públicas voltadas à redução desse consumo (Côrtes, 2013). Vale ressaltar que mais de 70\% da água é utilizada nos setores da agricultura e pecuária, cerca de 12\% serve para os setores da indústria e da mineração e, apenas 4\% é destinada à população (ANA, 2019 b; FAO, 2020). De acordo com o Conjuntura 2019:

A alta vulnerabilidade decorrente de um balanço hídrico desfavorável, associada a baixos investimentos em infraestrutura hídrica, principalmente dos sistemas de produção de água, e períodos de precipitações abaixo da média, podem agravar a situação e conduzir a períodos de crise hídrica por escassez, como verificado em diversas regiões do País nos últimos anos (ANA, 2019 b). 
Para enfrentamento dessa situação, várias ações vêm sendo desenvolvidas, como o programa Produtor de Água, que, em 2018, possuía 80 projetos voltados à conservação e recuperação dos recursos hídricos em diferentes fases de implementação e regiões do Brasil. A partir dessa iniciativa da ANA, muitas leis municipais regulamentaram políticas de pagamento por serviços ambientais (PSA ${ }^{3}$ ), beneficiando os produtores rurais participantes (ANA, 2019 b). Nesse sentido, considerando que os agricultores são atores chave da gestão dos recursos naturais, ao invés de pensar em punição é necessário incentivá-los à proteção ambiental, convidando-os a participarem das decisões (Kosoy, Corbera, \& Brown, 2008).

Da mesma forma, a meta 6.2 (Figura 3) prevê, até 2030, a garantia do acesso ao saneamento e à higiene adequados e equitativos para todos, com uma preocupação especial sobre os países de baixa renda, mulheres e meninas. No Brasil, até 2018, 63,4\% da população usufruía dos serviços de esgotamento sanitário geridos de forma segura, incluindo instalações para lavar as mãos com água e sabão (ANA, 2020). A ausência de tratamento de esgotos, com reflexos na saúde da população e na qualidade das águas, é um dos principais desafios do Brasil quanto ao alcance das metas do ODS 6 da Agenda 2030 (ANA, 2019 a).

Em 2020, devido à pandemia de Covid-19, a desigualdade no acesso ao saneamento básico no país, notadamente a falta de água potável ficou evidenciada. De acordo com os indicadores da ODS Brasil (2021), há aproximadamente seis milhões de pessoas sem água encanada e 78 milhões de pessoas sem tratamento de esgotos. Segundo Gonçalves e Silva (2020), a população mais vulnerável não apresenta condições, sequer, de lavar as mãos, medida recomendada pela Organização Mundial da Saúde (OMS) como uma das formas de prevenção do contágio. As autoras relatam que essa desigualdade em relação ao saneamento, bem como seu impacto na saúde, pode ser associada ao perfil racial e de classe, dos brasileiros mais afetados pela falta de políticas públicas.

Destaca-se ainda, na meta 6.2 (Figura 3), a preocupação com mulheres e meninas que, nos países de baixa renda, são as principais responsáveis pelas atividades domésticas, envolvendo a gestão do abastecimento de água, saneamento e saúde. Considera-se, ainda, o baixo acesso à educação pelo cumprimento dessas e outras funções, além da marginalização agravada pela falta de dignidade e segurança, sem sequer ter um local privado para ir ao banheiro (United Nations Water, 2021). Esses cuidados são extremamente relevantes, quando se observam publicações relacionadas à água e gênero (Quadro 3).

Quadro 3: Fatos publicados relacionados à água e gênero.

\begin{tabular}{|l|c|}
\hline \multicolumn{1}{|c|}{ Fatos sobre água e gênero } & Fonte $^{4}$ \\
\hline $\begin{array}{l}\text { Mulheres e meninas são responsáveis pela coleta de água em oito de cada 10 famílias com água fora das } \\
\text { instalações, portanto, reduzir o número da população com serviços limitados de água potável terá um } \\
\text { forte impacto de gênero. }\end{array}$ & $\begin{array}{c}\text { OMS \& UNICEF } \\
(2017)\end{array}$ \\
\hline $\begin{array}{l}\text { Um milhão de mortes a cada ano estão associadas a nascimentos em centros de saúde sem água potável. } \\
\text { As infecções são responsáveis por 26\% das mortes neonatais e 11\% da mortalidade materna. }\end{array}$ & $\begin{array}{c}\text { OMS \& UNICEF } \\
(2019)\end{array}$ \\
\hline $\begin{array}{l}\text { Embora forneça quase metade de toda a mão-de-obra agrícola em países de renda baixa e média, a } \\
\text { produtividade agrícola das mulheres é cerca de 20 a 30\% inferior à dos agricultores. }\end{array}$ & FAO (2017) \\
\hline $\begin{array}{l}\text { A redução do tempo necessário para buscar água de 30 para 15 minutos aumentou a frequência escolar } \\
\text { das meninas em 12\%, de acordo com um estudo na Tanzânia. }\end{array}$ & UNICEF (2019) \\
\hline $\begin{array}{l}\text { Cerca de 44 milhões de mulheres grávidas têm infecções de ancilostomíase relacionadas ao saneamento, } \\
\text { que representam um problema de saúde considerável nas sociedades em desenvolvimento. }\end{array}$ & UNICEF (2019) \\
\hline
\end{tabular}

Fonte: United Nations Water (2021).

Além do ODS 6, pode-se destacar que a meta 1.4 (ODS 1) também prevê a garantia que todos os homens e mulheres, especialmente os pobres e vulneráveis, tenham direitos iguais, bem como o acesso a serviços básicos até 2030. Outrossim, o

\footnotetext{
${ }^{3}$ Instrumento baseado no mercado para financiamento da conservação que considera os princípios do usuário-pagador e provedor-recebedor, pelos quais aqueles que se beneficiam dos serviços ambientais (como os usuários de água limpa) devem pagar por eles, e aqueles que contribuem para a geração desses serviços (como os usuários de terra a montante) devem ser compensados por proporcioná-los (Engel, Pagiola \& Wunder, 2008).

${ }^{4}$ Obtido em https://www.unwater.org/water-facts/gender/
} 
ODS 5 apresenta metas que visam alcançar a igualdade de gênero e o empoderamento de todas as mulheres e meninas, e o ODS 11 dispõe metas no intuito de tornar as cidades e os assentamentos humanos inclusivos, seguros, resilientes e sustentáveis (ONU, 2015).

Diante do exposto, é urgente a necessidade do fornecimento de água potável e instalações de saneamento e higiene adequadas em residências, nos locais de trabalho e instituições de ensino, garantindo, de forma igualitária, que todas as pessoas tenham uma vida segura, produtiva e saudável. A meta 6.3 (Figura 3) é referente à necessidade de melhoria de qualidade da água, produzindo água segura para todos. Entretanto, a ANA ainda não dispõe de dados suficientes que permitam calcular o indicador com segurança quanto à qualidade da água distribuída (ANA, 2019 a). No Brasil, até 2018, apenas 51,9\% das águas residuais eram tratadas de forma segura e 77,5\% dos corpos hídricos apresentavam boa qualidade de água (ANA, 2020).

Em 2013, a ANA lançou a Rede Nacional de Monitoramento da Qualidade da Água (RNQA) e criou o programa Qualiágua, a fim de pagar por resultados, estimulando a ampliação e continuidade do monitoramento pelas redes. Assim, em 2018, havia 2.873 pontos de monitoramento da qualidade da água em operação em 24 Unidades de Federação, com a previsão de implantação de mais 4.534. Nesse sentido, dados do monitoramento do RNQA de 2018 apontam valores mais críticos da Demanda Bioquímica de Oxigênio (DBO) em corpos hídricos nas regiões metropolitanas do Rio de Janeiro, Belo Horizonte e São Paulo. Além disso, esses locais também apresentaram aumento de fósforo nos rios, propiciando a eutrofização, o que também aconteceu na região Nordeste do Brasil e na região metropolitana de Curitiba, na porção superior do Rio Iguaçu. Quanto ao Índice de Qualidade das Águas (IQA ${ }^{5}$ ), os resultados mostram valores dentro da faixa de qualidade "boa" predominante no interior do país. No entanto, encontrou-se sensibilidade nas grandes cidades brasileiras, evidenciando os desafios relacionados à universalização do saneamento básico e à importância de boa infraestrutura para o controle da poluição hídrica de origem difusa no meio urbano (ANA, 2020).

Sobre a eficiência dos processos já relatados, a meta 6.4 (Figura 3) aponta a necessidade de assegurar retiradas sustentáveis para o abastecimento de água doce, favorecendo o enfrentamento da escassez de água. Nesse sentido, em 2018, o investimento em alterações na eficiência do uso da água no Brasil foi de $\mathrm{R} \$ 22,06$ por $\mathrm{m}^{3}$. No mesmo ano, o nível de stress hídrico, proporção entre a retirada de água doce e o total desse recurso disponível no país, foi de 1,76\% (ANA, 2020). De acordo com o Conjuntura Brasil, "o crescimento das demandas hídricas no Brasil, a partir do aumento da população e das atividades econômica intensivas em uso de água, contribui para o aumento do stress hídrico, com o passar dos anos" (ANA, 2019 a, p. 42). Vale ressaltar que as regiões mais críticas são: Sudeste (uso da água para abastecimento humano, irrigação e indústria), Sul (água usada para irrigação do arroz por meio de inundação) e Nordeste (baixa disponibilidade hídrica).

Conforme a meta 6.5 (Figura 3), a gestão integrada dos recursos hídricos e a cooperação transfronteiriça também devem ser implementadas até 2030. No Brasil, essa gestão dos recursos hídricos é objeto da Política Nacional de Recursos Hídricos, Lei № 9.433/1997, que inclui “a utilização racional e integrada dos recursos hídricos” (Brasil, 1997). Nesse sentido, o grau de implementação da gestão integrada de recursos hídricos no Brasil até 2019 foi de 63,1\%. Já a proporção de bacias hidrográficas e aquíferos transfronteiriços abrangidos por um acordo operacional de cooperação, até 2019 , foi de $61,8 \%$. Nessa direção, é fundamental considerar a importância da preservação dos processos ecológicos essenciais, pois há uma relação intrínseca entre os ecossistemas e a disponibilidade hídrica. Assim, a meta 6.6 (Figura 3) estabelece que, até 2020, deveriam ser restaurados e protegidos os ecossistemas relacionados com a água, incluindo montanhas, florestas, zonas úmidas, rios, aquíferos e lagos. Todavia, mesmo que esse tema também faça parte do Art. 225 da Constituição Federal do Brasil, ainda há muitos ecossistemas a serem recuperados no país. Até 2015, havia apenas 10,3\% de alterações positivas nos ecossistemas

${ }^{5}$ O IQA foi originariamente desenvolvido em 1970, nos EUA. O IQA citado neste estudo inclui 9 parâmetros: temperatura, pH, oxigênio dissolvido, DBO, colimetria, nitrogênio total, fósforo total, sólidos totais e turbidez (ANA, 2020). 
aquáticos do país (ANA, 2020).

Em relação à segurança hídrica, as metas 6.a e 6.b (Figura 3), dispõem que, até 2030, caberá:

"6.a [...] ampliar a cooperação internacional e o apoio à capacitação para os países em desenvolvimento em atividades e programas relacionados à água e saneamento, incluindo a coleta de água, a dessalinização, a eficiência no uso da água, o tratamento de efluentes, a reciclagem e as tecnologias de reuso, assim como, no item 6.b., apoiar e fortalecer a participação das comunidades locais, para melhorar a gestão da água e do saneamento (Agenda 2030, 2015).

Nessa direção, a proporção de unidades administrativas locais com políticas e procedimentos estabelecidos objetivando à participação local na gestão da água e saneamento do país foi de 49\% até 2017 (ANA, 2020). Entretanto, Barraqué (2017) descreve que só é possível realizar os planos de resiliência urbana, conforme previsto no Acordo de Paris, levando-se em consideração as secas prolongadas e severas. Essa dificuldade está extremamente relacionada ao uso da terra, uma vez que para recuperar os ecossistemas torna-se necessário o deslocamento de populações, geralmente de baixa renda, moradores de áreas de risco. Levando em conta que a proteção dos recursos hídricos está diretamente associada à gestão ambiental, é de fundamental importância que as políticas públicas municipais também orientem a ocupação do território do município considerando a preservação dos recursos hídricos disponíveis na sua região e bacias hidrográficas, corroborando para o que prevê a Agenda 2030.

Diante do exposto, verifica-se que, apesar de diversas ações de implementação das metas do ODS 6, no Brasil, ainda há lacunas e desafios para, efetivamente, assegurar a disponibilidade e gestão sustentável da água e saneamento para todos, conforme a previsão desse objetivo. Essas metas, pactuadas entre 193 Estados-Membros das Nações Unidas em 2015, representam um grande obstáculo a ser vencido por todos os países (ANA, 2019 a).

\section{Considerações Finais}

A intensificação dos problemas referentes aos aspectos sociais, ambientais e econômicos impulsionaram a necessidade de negociações internacionais com objetivos globais. Dessa forma, com o avanço do conhecimento científico aliado às tentativas de muitos países em promover formas alternativas de desenvolvimento integrando o tripé da sustentabilidade resultaram em acordos e tratados firmados em conferências sobre o meio ambiente. Assim, a busca por melhores estratégias, metas e ações pautadas sob uma perspectiva socioeconômica e ambiental amplia-se anualmente.

Nessa perspectiva, destacam-se os eventos internacionais: Conferência de Estocolmo (1972); Rio-92 (1992); Rio + 10 (2002); Rio + 20 (2012); Conferências das Partes - COP (anuais, de 1995 a 2019). Fica a expectativa para que a COP-26 aconteça, com compromissos climáticos mais ambiciosos por parte dos países signatários do Acordo de Paris. Espera-se, ainda, que o Brasil assuma um papel de relevância no cumprimento desse tratado, avançando na redução de emissões de GEE, entre outras metas relevantes.

A respeito da implementação do ODS 6 no Brasil, verificou-se a concretização parcial de suas metas, consideradas como inciativas que precisam ser aprimoradas por meio de ações, projetos e novas políticas públicas que garantam aos brasileiros o acesso à agua potável e ao saneamento básico. Para tanto, é extremamente relevante o compromisso da ANA, no monitoramento e atualização dos dados relacionados aos indicadores do ODS 6, na direção de sua efetivação.

Por fim, almeja-se que essa revisão contribua para o acesso a informações, de forma sistematizada, que contribuam com pesquisas futuras sobre meio ambiente, mudanças climáticas e Objetivos do Desenvolvimento Sustentável no país e subsidiem ações voltadas à sustentabilidade ambiental. 


\section{Referências}

Agenda 2030 (2015). A Agenda 2030 para o Desenvolvimento Sustentável. http://www.agenda2030.com.br/sobre/

Alcântara, L. R. P., Silva, M. E. R., Santos Neto, S. M., Lafayette, F. B., Coutinho, A. P., Montenegro, S. M. G. L., \& Antonino, A. C. D. (2020). Mudanças climáticas e tendências do regime pluviométrico do Recife. Research, Society and Development, 9(3), 1-21. http://dx.doi.org/10.33448/rsd-v9i3.2583

ANA (2019 a). Agência Nacional de Águas (Brasil). ODS 6 no Brasil: visão da ANA sobre os indicadores/ Agência Nacional de Águas. Brasília: ANA.

ANA (2019 b). Agência Nacional de Águas (Brasil). Conjuntura dos recursos hídricos no Brasil 2019: informe anual / Agência Nacional de Águas. Brasília: ANA.

ANA (2020). Agência Nacional de Águas (Brasil). Conjuntura dos recursos hídricos no Brasil 2020: informe anual / Agência Nacional de Águas e Saneamento Básico. Brasília: ANA.

Assad, E. D., Martins, S. C., Cordeiro, L. A. M. \& Evangelista, B. A. (2019). Sequestro de carbono e mitigação de emissões de gases de efeito estufa pela adoção de sistemas integrados. Brasília: Embrapa.

Barbi, F. (2017). O desafio das mudanças climáticas: a internalizarão política das questões climáticas no Brasil e na China. In: Ferreira, L (org.). O desafio das mudanças climáticas: os casos Brasil e China. Jundiaí: Paco Editorial.

Barraqué, B. (2017). COP 22: water-related adaptation to climate change in large cities. In: Governança da Água no contexto da escassez hídrica (1a ed.). São Paulo: IEE-USP, UFABC e GovAmb.

Beeson, M., \& Mc Donald, M. (2013). The politics of climate change in Australia. Australian Journal of Politics and History, 59(3), 331-348. DOI: 10.1111 / ajph.12019

Bernauer, T. (2013. Política de Mudança Climática. Revisão Anual da Ciência Política, 16, 421-448. https://doi.org/10.1146/annurev-polisci-062011-154926

Bezerra, V. A. (2019). Apresentação. In: Menezes, H. Z (org). Os objetivos de desenvolvimento sustentável e as relações internacionais. João Pessoa: Editora UFPB.

Bordalo, C. A. L. (2012). A "crise" mundial da água vista numa perspectiva da geografia política. GEOUSP: Espaço e Tempo, 16(1), 66-78. https://doi.org/10.11606/issn.2179-0892.geousp.2012.74270

Brasil (1997). Lei $N^{o}$ 9.433, de 09 de janeiro de1997. Política Nacional de Recursos Hídricos. Diário Oficial da República Federativa do Brasil, Poder Executivo, Brasília: 1997.

Camargo, L. A. (2015). Os regimes internacionais enquanto ações de governança global. In: Costa \& Silva, A., Araújo, E. L. (Coord.). Direito ambiental: temas polêmicos. Curitiba: Juruá.

Carvalho, E. F. (2011). Meio ambiente e direitos humanos (2a ed.). Juruá.

Climate Ambition Summit. (2020). Co-convened by the United Nations, the United Kingdom and France. In: Partnership with Chile and Italy. https://www.climateambitionsummit2020.org/

Côrtes, P. L. (2013). Conception and development of a system used to organize and facilitate access to environmental information. Journal of Information Systems and Technology Management, 10(1), 161-176. https://doi.org/10.1590/S1807-17752013000100010

E3G. (2020). Estrategistas mundiais na economia política das mudanças climáticas. Coronavírus altera agenda de reuniões ambientais. https://dialogochino.net/pt-br/mudanca-climatica-e-energia-pt-br/34325/

Engel, S., Pagiola, S., \& Wunder, S. (2008). Designing payments for environmental services in theory and practice: an overview of the issues. Ecological Economics, 65(4), 663-674. https://doi.org/10.1016/j.ecolecon.2008.03.011

FAO (2020). The State of Food and Agriculture. Overcoming water challenges in agriculture. https://doi.org/10.4060/cb1447en

Fleury, L. C., Miguel, J. C. H., \& Taddei, R. (2019). Mudanças climáticas, ciência e sociedade. Sociologias, 21(51), 18-42. https://doi.org/10.1590/151745220215101

FARN. (2020). Fundação Ambiente Y Recursos Naturales, Argentina. Declaração de Enrique Maurtua Konstantinidis, assessor-sênior sobre o clima. https://dialogochino.net/pt-br/mudanca-climatica-e-energia-pt-br/34325/

G1 Natureza. (2020). Brasil fica fora de evento da ONU que reúne países que anunciaram metas ambiciosas para redução de gases de efeito estufa. https://g1.globo.com/natureza/noticia/2020/12/10/brasil-fica-fora-de-evento-da-onu-que-reune-paises-que-anunciaram-metas-ambiciosas-para-reducao-degases-de-efeito-estufa.ghtml

Galvão, T. G., \& Monteiro, G. A. (2019). ODS 6 "Assegurar a disponibilidade e gestão sustentável da água e saneamento para todas e todos”. In: Menezes, H. Z. (Org.). Os objetivos de desenvolvimento sustentável e as relações internacionais. João Pessoa: Editora UFPB.

Gil, A. C. (2002). Como classificar as pesquisas. (4a ed.), Atlas S/A.

Gonçalves, L. S., \& Silva, C. R. (2020). Pandemia de Covid-19: sobre o direito de lavar as mãos e o "novo" marco regulatório de saneamento básico. Revista Científica Foz, 3(1), 70-91. 
Granziera, M. L. M., \& Silva, I. M. G. (2019). Os Objetivos do Desenvolvimento Sustentável (ODS) e a legislação brasileira sobre abastecimento humano: mecanismos de efetividade. Leopoldianum, 45(125), 125-136.

IPCC (2014). Intergovernmental Panel on Climate Change. Climate Change 2014: Synthesis Report. Contribution of Working Groups I, II and III to the Fifth Assessment Report of the Intergovernmental Panel on Climate Change. Geneva: IPCC.

Jacobi, P. R., Guerra, A. F. S., Sulaiman, S. N., \& Nepomuceno, T. (2011). Mudanças climáticas globais: a resposta da educação. Revista Brasileira de Educação, 16(46), 135-269. https://doi.org/10.1590/S1413-24782011000100008

Keohane, R. O., \& Victor, D. G. (2011). The regime complex for climate change. Perspectives on Politics, 9(1), 7-23. https://doi.org/10.1017/S1537592710004068

Kosoy, N., Corbera, E., \& Brown, K. (2008). Participação em pagamentos por serviços ecossistêmicos: estudos de caso da Floresta Lacandon, México. Geoforum, 39(6), 2073-2083.

Lima, M. I. L. S., \& Granziera, M. L. M. (2018). Direito Humano à Água e a Perspectiva Econômica para a Sustentabilidade Hídrica. Revista do CNMP: água, vida e direitos humanos, 7, 13-36. Brasília: Conselho Nacional do Ministério Público.

Lopes, L. (2018). Agenda 2030 para o desenvolvimento sustentável. PNUD do Brasil. https://slideplayer.com.br/slide/12020310/

Marengo, J. A., Nobre, C. A., Seluchi, A. E., Cuartas, A., Alves, L. M., Mediondo, E. M., Obregón, G., \& Sampaio, G. (2015). A seca e a crise hídrica de 2014 - 2015 em São Paulo. Revista USP, 106, 31-44. https://doi.org/10.11606/issn.2316-9036.v0i106p31-44

Menezes, H. Z. (2019). Os objetivos de desenvolvimento sustentável e as relações internacionais. Editora UFPB.

Miranda, D. T., \& Decesaro, G. D. M. (2018). Os impactos e as consequências gerados pela urbanização acelerada às águas urbanas. Revista TécnicoCientífica do CREA-PR, 13, 1-9.

Neves, J. T., \& Bizawu, K. (2019). O extrativismo da madeira na Amazônia e seus impactos ambientais: a contribuição do protocolo de Kyoto para o desenvolvimento sustentável. Revista Argumentum, 20(2), 465-483.

Nobre, C. A., Salazar, L. F., Oyama, M., Cardoso, M., \& Sachs, I. (2007). Estratégias de transição para o século XXI: desenvolvimento e meio ambiente. São Paulo: Studio Nobel.

Observatório do Clima. (2020). Dez fatos que marcaram o clima em 2020. https://www.oc.eco.br/en/dez-fatos-que-marcaram-o-clima-em-2020/

ODIN. (2021). Open Data Inventory. Open Data Watch. https://odin.opendatawatch.com/

ODM Brasil. (2000). Os Objetivos de Desenvolvimento do Milênio. https://odmbrasil.gov.br/

ODS Brasil. (2021). Indicadores Brasileiros para os Objetivos de Desenvolvimento Sustentável. https://odsbrasil.gov.br/home/agenda.

ONU (2015). Organização das Nações Unidas. Transformando Nosso Mundo: A Agenda 2030 para o Desenvolvimento Sustentável. 〈http://www.itamaraty.gov.br/images/ed_desenvsust/Agenda2030-completo-site.pdf〉.

Pereira, A. S., Shitsuka, D. M., Parreira, F. J., \& Shitsuka, R. (2018). Metodologia da Pesquisa Científica. UFMS.

Rei, F. C. F., Gonçalves, A. F., \& Souza, L. P. (2017). Acordo de Paris: reflexões e desafios para o regime internacional de mudanças climáticas. Veredas do Direito, 14(29), 81-99. https://doi.org/10.18623/rvd.v14i29.996

RibRichter, B. D. (2015). Em busca da água: um guia para passar da escassez à sustentabilidade. Oficina de Textos.

Silva, J. L., \& Samora, P. R. (2019). Os impactos da crise hídrica sobre a população do município de Campinas/São Paulo (2012-2016). Revista Brasileira de Gestão Urbana, 11(e20180210), 1-14. https://doi.org/10.1590/2175-3369.011.e20170210

Somlyódy, L., \& Varis, O. (2006). Freshwater under pressure. International Review for Environmental Strategies, 6(2), 181-204.

Tundisi, J. G. (2003). Água no século 21: enfrentando a escassez. RIMA/IIE.

Tundisi, J. G., \& Matsumura-Tundisi, T. (2015). As múltiplas dimensões da crise hídrica. Revista USP, 106, 21-30. https://doi.org/10.11606/issn.23169036.v0i106p21-30

UNCT (2015) - Nações Unidas Brasil. Os Objetivos de Desenvolvimento Sustentável no Brasil. https://brasil.un.org/pt-br/sdgs

UNFCCC (2020a). United Nations Framework Convention on Climate Change. Nationally Determined Contributions (NDCs): The Paris Agreement and NDCs, https://unfccc.int/nationally-determined-contributions-ndcs

UNFCCC (2020b). United Nations Framework Convention on Climate Change. Conference of the Parties (COP). https://unfccc.int/process/bodies/supremebodies/conference-of-the-parties-cop.

UN-ECOSOC. (2019). United Nations Economic and Social Council. Progress towards the Sustainable Development Goals. Special edition. Report of the Secretary-General. E/2019/68, ONU.

United Nations Water (2021). Water and Gender. <http://www.unwater.org/waterfacts/gender/>

USA. (2021). United States government. Inauguration of the President of the United States. https://www.usa.gov/inauguration 